\title{
A New Low-Cost Plastic Solar Collector
}

\author{
Luis E. Juanicó and Nicolás Di Lalla \\ Bariloche Atomic Center, Rio Negro, 8400 Bariloche, Argentina \\ Correspondence should be addressed to Luis E. Juanicó; juanico@cab.cnea.gov.ar
}

Received 4 July 2013; Accepted 24 July 2013

Academic Editors: C. Koroneos and P. Poggi

Copyright (C) 2013 L. E. Juanicó and N. Di Lalla. This is an open access article distributed under the Creative Commons Attribution License, which permits unrestricted use, distribution, and reproduction in any medium, provided the original work is properly cited.

\begin{abstract}
An innovative solar collector based on a long plastic hose that is connected directly in series from the district water grid to consumption is presented. It takes advantage of plastic tubing to develop a simple self-construction collector that costs about 70 dollars for a one-family unit. In addition, due to its solar-pond configuration, it could achieve a good thermal performance, as it was demonstrated by modeling.
\end{abstract}

\section{Introduction}

The photovoltaic panel is the preferred renewable technology to obtain electricity from homes in developed countries, but regarding new high-efficiency home appliances this consumption is expected to decrease in the future. On the other hand energy consumption for heating water will remain unchanged considering that domestic heaters have reached their ideal efficiency. Although this represents only $15 \%$ of the total household energy demand in cold-climate developed countries, it increases up to $40 \%$ in developing countries with temperate climate and even more in poorer tropical ones. This is contradictory; whereas solar collectors have a large market in developed countries, this is minimal in developing ones. This discrepancy has a correlation regarding the evolution of solar technology which should be studied considering that solar collectors produce energy five times cheaper than PVs [1].

It is well known that a small solar collector based on modern vacuum tubes $\left(2-3 \mathrm{~m}^{2}\right)$ can satisfy the one-family demand anywhere. This design is more suitable for cold high-latitude locations than flat collectors since its cylindrical shape receives almost twice as much solar irradiation [2] and minimizes heat losses as well. Nowadays more than $90 \%$ of the worldwide market is supplied by Chinese manufactured vacuum-tube collectors with final prices as low as 500 USD in developed countries with large solar markets. On the other hand the scenario is quite different in developing countries. Due to the small size of the market in these countries, prices generally exceed the previous level by far. Actually, prices are double or more in origin due to the low scale of trading involved, and the final price paid by users can be even higher because of the following.

(1) Freight cost within the country adds up to 200 U\$D. Many developing countries are large with lowpopulation density and a weak transportation infrastructure, so freight costs for fragile devices are usually high.

(2) Costs of installation add up to $400 \mathrm{U} \$ \mathrm{D}$. A large country with small market and weak dealer's network is a big drawback; in this sense the complexity of the heat-pipe technology does not help.

(3) Perception of risk by users is usually high due to several reasons.

(i) Due to lack of national regulations and certifications, user's uncertainties regarding the annual yield of solar collectors are very high.

(ii) Since dealers are small businessmen without the support of a large enterprise, user's doubts about warranty, postsell services, and so forth are often very high.

(iii) The risk of theft or vandalism is not negligible.

Certainly there are barriers for the development of solar markets in developing countries (beyond economic issues) not 


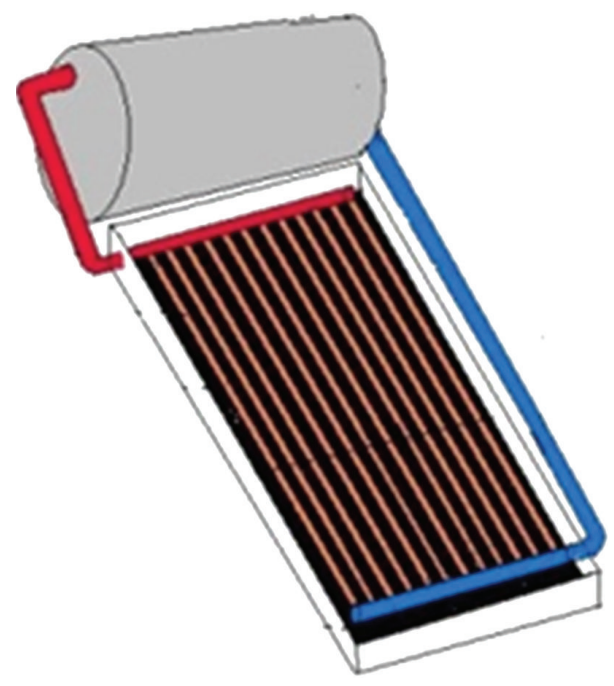

FIGURE 1: Schematic drawing of a conventional flat collector.

solved for the vacuum-tube technology since its complexity implies that these collectors must be built by a faraway large manufacturer and therefore with high freight costs, needing professional installation and so forth. Leading technologies are going in the opposite direction than what developing countries need.

On the other hand the demand of sanitary hot water (down to $45^{\circ} \mathrm{C}$ ) in temperate and tropical countries is a good niche market for local manufacturers [3]. The low temperature difference involved allows them to build cheaper collectors avoiding expensive solutions like selective paints, inner-gas arc welding, vacuum tubes, and so forth, but the small size of local markets does not help. Governments usually hesitate between supporting small local manufacturers and supporting massive importation of Chinese collectors (which is often frowned upon by their scientific community) and, ultimately, do not make any decision. Still up to now most people in developing countries have neither used a solar collector nor known anybody who did, and, thus, the wheel never begins to turn.

Actually this problem exceeds the scientific approach that usually focuses on maximizing a collector's efficiency. Instead and by taking a holistic approach, these problems could be solved by using low-cost materials universally available that could be easily assembled in a simple home-made collector. At first glance plastic appears as an excellent choice, but present designs do not support this choice as will be discussed later. This paper presents a new design that could solve this deficiency.

\section{Thermal-Hydraulic Analysis of Flat Solar Collectors}

2.1. Conceptual Analysis of Conventional Flat Collectors. Flat solar collectors have followed the same conceptual design illustrated in Figure 1 from their beginnings in the sixties. It consists of a black metal plate absorbing solar radiation and

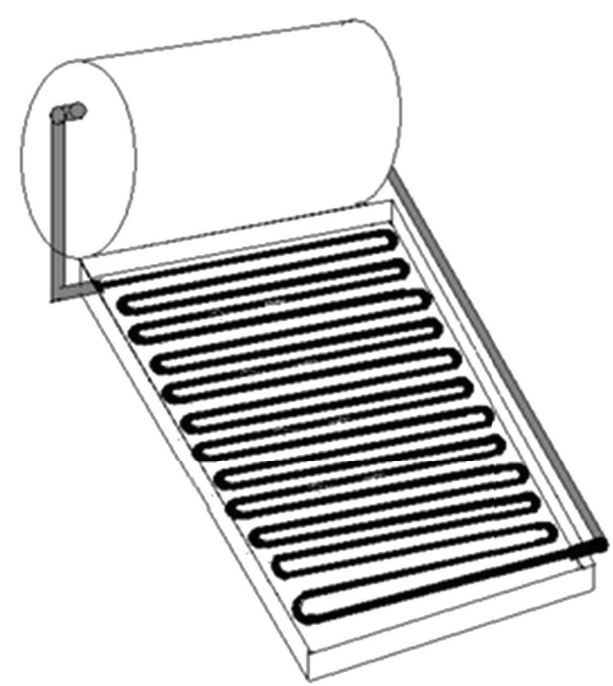

FIGURE 2: Schematic drawing of a conventional collector built with a single hose.

transferring it to an assembly of parallel tubes connected to the upper storage tank through the hot leg of a hydraulic loop that is closed by means of its cold leg and is driven by natural convection. Heat losses are minimized by mounting glazing covers onto the collector and insulating its back side as well.

The use of many parallel tubes short in length is mandatory for minimizing hydraulic losses. The difference of densities between both legs can barely pump the coolant flow through this grid of tubes connected to two large flow collectors. For example, for a tank 2 meters above the collector and a temperature difference of $40^{\circ} \mathrm{C}$, the buoyancy pressure is only $3 \mathrm{~cm}$ of water column. This design emerges as a compromise solution between hydraulic and thermal behaviors. Ideally, the heat absorbed is maximized by using a homogeneous mesh of infinite thin cooling channels (so that transversal thermal gradients in the absorbing plate are minimized and the absorbing area is not reduced); meanwhile the hydraulic flow is maximized by using a few channels of a large diameter and short in length. In addition, the efficiency is improved by using tubes of high thermal conductivity, like copper.

The copper collector was generalized in the seventies and continues to be used today for home-made collectors, since it is relatively easy to weld the thin tubes to both large flow collectors. However, in the last two decades the increasing copper costs together with new welding technologies have substituted copper with aluminum or stainless steel but keeping the same conceptual design; perhaps the vacuum tube (specially the heat pipe) has been the only conceptual innovation observed.

The natural-convection grid-type collector continues to be used today because it apparently leads to the simplest solution, but actually it implies strong limitations regarding opportunities created by new plastic materials. From here, it is clear that the simplest solution would be achieved by using a single long hose (illustrated in Figure 2), but this choice does not work within the natural-convection approach due to its (highest) hydraulic restriction. Herein, for example, a 


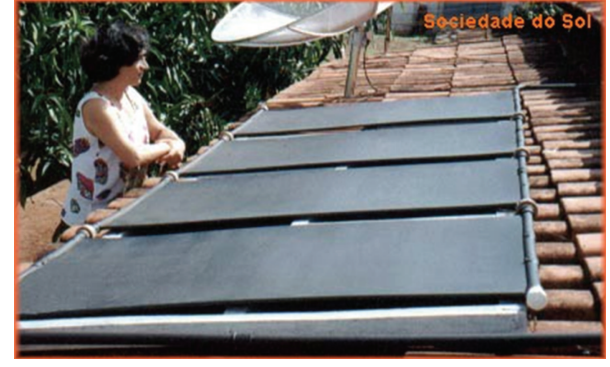

FIGURE 3: View of the polycarbonate collector.

collector based on one $100 \mathrm{~m}$ hose has a hydraulic restriction 10,000 times larger than a grid assembled with one hundred $1 \mathrm{~m}$ long parallel tubes. On the other hand, this last design requires numerous sealed fittings that imply major concerns that we will discuss now.

Despite enormous advances in plastic tubing during the last two decades, all fittings can be classified into three kinds.

(1) Barb fittings. These fittings are used with more elastic tubing materials, like LDPE. It provided at best a medium-quality fitting, and, so, it is not suitable for assembling a grid with many connections. In addition, it requires numerous tee-type connections in order to assemble each thin tube to both flow collectors.

(2) Threaded pipe joints. This kind of fittings is used on more rigid materials, like PVC. It provides a goodquality fitting, but considering the grid scheme it implies many overlapping joints (double-threaded joints and change-of-section joints). So, the increase in the number of fittings increases the risk of failure, as well as costs.

(3) Thermofusion joints. The HDPE pipes can be joined by thermal fusion to form a joint that is as strong as the pipe itself and is almost leak free, but its application to the grid layout is too cumbersome since it would require welding simultaneously all parallel tubes to each flow collector or using too many overlapping joints.

Summarizing, the application of new plastic tubing to standard collectors has strong limitations that annul their apparent advantages. The next design must be created on a new thermal-hydraulic paradigm that allows changing the grid-type design.

\subsection{Analysis of Previous Original Designs of Plastic Collec-} tors. Several designs have already been developed specially for plastic collectors. Let us analyze now three innovative designs: (1) the polycarbonate-integrated collector; (2) the roof-integrated collector, and (3) the tube-integrated collector.

2.2.1. The Polycarbonate-Integrated Collector. The polycarbonate collector shown in Figure 3 has been in use for more than a decade in Brazil having hundreds of units successfully built [4]. Modern polycarbonate sheets having UV filters with good mechanical resistance carry a 10 -year lifetime warranty. This collector integrates the absorbing plate and the hydraulic grid in one sheet of transparent alveolar polycarbonate in which its bottom is painted black and both headers are attached to PVC large tubes with a long slot drilled along their length. This way, this design solves in an elegant manner the cumbersome manufacture of the grid by using just one low cost $\left(20 \mathrm{USD} / \mathrm{m}^{2}\right)$ standard piece. However, to drill a long and narrow slot with exigent dimensional tolerance requires the use of specialized tools, and so this technology is prohibitive as a home-made solution.

On the other hand, regarding the thermal-hydraulic configuration this collector belongs in the conventional category. Thus, its performance is poor since no upper glazing, selective paint, or back insulation is used. This concern is minor in tropical countries, but since these are the poorest ones in the manufacturing process there is a major barrier; on the other hand for middle-income countries with temperate climates its low efficiency is a major drawback. The next design solves this problem by means of a new approach.

2.2.2. The Water-Pond Collector. The roof-integrated solar roof has been recently presented at a conceptual level for horizontal roofs [5] and for inclined roofs $[6,7]$. This is an active system that integrates a large water pond in the roof built with long water cushions hydraulically interconnected mounted on the roof. It uses water redistribution to become a configurable roof working with the household space heating system (see Figure 4). This way, four working configurations are obtained.

(1) During winter days the water pond is filled in order to heat the water with solar irradiation which in turn heats the indoor space by infrared radiation.

(2) During winter nights the heated water is drained to an insulated tank from where it is used for the infloor space heating system and hot water consumption.

(3) During summer days the water pond is filled in order to limit the increase in temperature. This way, this water roof is used as a "thermal buffer;" while a concrete roof could easily reach $80^{\circ} \mathrm{C}$ in a sunny day [8] this water roof keeps the temperature down to $40^{\circ} \mathrm{C}[6,7]$. This feature has been extensively used in other previous designs, like the Skyterm [9].

(4) During summer nights the previous behavior can be enhanced by draining the water pond into a garden reflecting pool in order to be cooled.

Despite its high configurability, maybe the major contribution of this system is that it includes a water pond instead of the natural-convection scheme. Hence, its thermal performance is noticeably improved since the whole water inventory is heated simultaneously instead of only a small part overheated in the collector. To understand this key factor, let us compare the solar efficiency of the solar collector with 


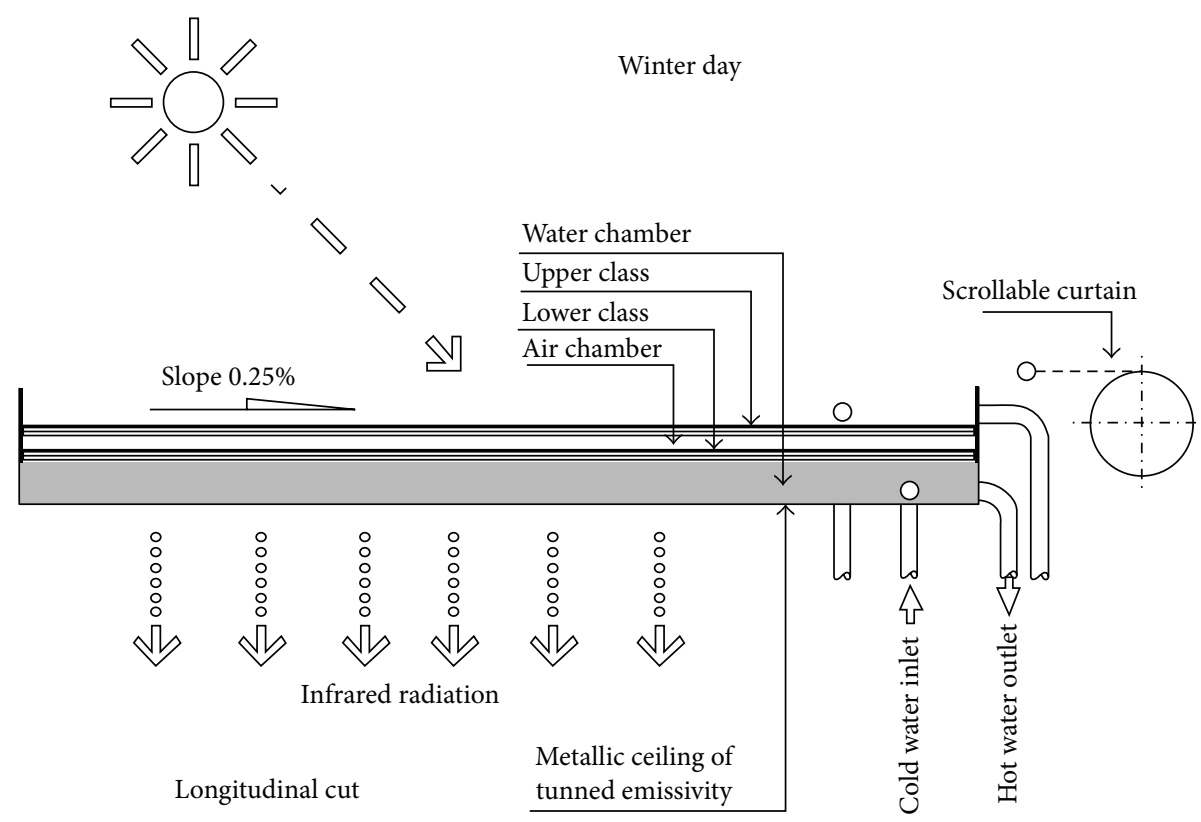

FIGURE 4: Schematic drawing of water-pond roof on winter-day configuration.

the water pond. The thermal efficiency $(\mu)$ for any collector can be described by a linear function as

$$
\mu=a_{0}-a_{1} \frac{\left(T_{m}-T_{a}\right)}{I_{n}},
$$

where $a_{0}$ is the efficiency obtained for the non-heat-losses condition (if the mean temperature, $T_{m}$, is equal to ambient temperature, $\left.T_{a}\right), a_{1}\left(\mathrm{~W} / \mathrm{m}^{2 \circ} \mathrm{C}\right)$ is the linear coefficient related to heat losses, and $I_{n}$ is the normal flux of solar irradiance $\left(\mathrm{W} / \mathrm{m}^{2}\right)$. The mean temperature $T_{m}$ in the grid collector is determined by the average between the inlet cold temperature $\left(T_{c}\right)$ and the exit $\left(T_{h}\right)$ hot temperature. Since the cooling flow is driven just by this temperature difference, $\Delta T$, it could easily rise to $40^{\circ} \mathrm{C}$ [10]. So, let us consider for illustrative purposes a standard collector in which $T_{a}=10^{\circ} \mathrm{C}, T_{c}=$ $30^{\circ} \mathrm{C}$, and $\Delta T=40^{\circ} \mathrm{C}$. Hence, $T_{h}=70^{\circ} \mathrm{C}$, and thus $T_{m}=$ $50^{\circ} \mathrm{C}$, obtaining $T_{m}-T_{a}=40^{\circ} \mathrm{C}$. On the other hand the mean temperature of the equivalent water pond is just $30^{\circ} \mathrm{C}$ since $T_{c}=T_{h}=T_{m}$, and thus $T_{m}-T_{a}=20^{\circ} \mathrm{C}$, half of the previous case. Therefore, according to (1) the solar efficiency of a water pond is noticeably higher than a standard collector of similar quality. Although this comparison can only be quantified by setting the right $\left(a_{0}, a_{1}\right)$ parameters, it is clear that this trend will be greater for low-quality collectors (i.e., having higher $a_{1}$ values) like the ones used in developing countries. Tables 1 and 2 show bibliographic values $[10,11]$ of $\left(a_{0}, a_{1}\right)$ for different collectors and water ponds, respectively, in which the efficiency is the merit figure. The use of water ponds shows an improvement of up to $200 \%$ for the poorest-quality collectors against 38\% for the best ones. However, note that the cheaper (unglazed) collector cannot warm water up to $30^{\circ} \mathrm{C}$ in this cold ambient $\left(10^{\circ} \mathrm{C}\right)$ and neither can the equivalent water pond $(\mu=25 \%)$. Therefore, the middle-quality collector emerges as the best compromise
TABLE 1: Characteristic average parameters and results for standard flat solar collectors. Efficiency calculated for $T_{a}=10^{\circ} \mathrm{C}, T_{c}=30^{\circ} \mathrm{C}$, $T_{m}=50^{\circ} \mathrm{C}$, and $I_{n}=600 \mathrm{~W} / \mathrm{m}^{2}{ }^{\circ} \mathrm{C}$.

\begin{tabular}{lccc}
\hline Collector type & $a_{0}(\#)$ & $a_{1}\left(\mathrm{~W} / \mathrm{m}^{2}{ }^{\circ} \mathrm{C}\right)$ & Efficiency $(\%)$ \\
\hline Unglazed & 0.85 & 18 & -0.35 \\
Single glazing & 0.80 & 8 & 0.27 \\
Double glazing & 0.75 & 5 & 0.42 \\
\hline
\end{tabular}

solution between improvement and performance; while its improvement is remarkable $(+96 \%)$ its efficiency is good (53\%) too.

This comparison is even better when the full heating process is analyzed. Let us consider both single-glazing collectors starting in the morning with their water inventory at ambient temperature $\left(T_{\text {tank }}=T_{a}=10^{\circ} \mathrm{C}\right)$ that is desired to heat up to $45^{\circ} \mathrm{C}$. The standard collector always works at $\Delta T=$ $40^{\circ} \mathrm{C}$, but its $T_{m}$ is increased throughout the day following the $T_{\text {tank }}$ increases, and so its efficiency is decreased from an initial $53 \%\left(T_{c}=10^{\circ} \mathrm{C}, T_{h}=50^{\circ} \mathrm{C}\right.$, and $\left.T_{m}=30^{\circ} \mathrm{C}\right)$ to a final $6 \%\left(T_{c}=45^{\circ} \mathrm{C}, T_{h}=85^{\circ} \mathrm{C}\right.$, and $\left.T_{m}=65^{\circ} \mathrm{C}\right)$, and hence this temperature level could hardly be achieved even for the high normal flux $\left(I_{n}=600 \mathrm{~W} / \mathrm{m}^{2}\right)$ considered. For this reason the cheapest flat collectors cannot collect solar energy during evening hours, as it is an usual observation.

On the other hand the water pond starts in the morning with an impressive efficiency of $80 \%\left(T_{c}=T_{h}=T_{m}=\right.$ $10^{\circ} \mathrm{C}$ ) that decreases down to $33 \%$, which is five times greater than the collector's efficiency at that moment. So, the water pond collects energy throughout the day in a much more convenient manner than the conventional collector.

This promising design has been developed only up to a conceptual level, although it has a good chance of success. However, the manufacture of large plastic waterproof bags 
TABLE 2: Characteristic parameters for water-pond collectors. Efficiency calculated for $T_{a}=10^{\circ} \mathrm{C}, T_{c}=T_{m}=30^{\circ} \mathrm{C}$, and $I_{n}=600 \mathrm{~W} / \mathrm{m}^{2}{ }^{\circ} \mathrm{C}$; improvement related to Table 1 .

\begin{tabular}{lcccc}
\hline Collector type & $a_{0}(\#)$ & $a_{1}\left(\mathrm{~W} / \mathrm{m}^{2}{ }^{\circ} \mathrm{C}\right)$ & Efficiency $(\%)$ & Improvement $(\%)$ \\
\hline Unglazed & 0.85 & 18 & 0.25 & 200 \\
Single glazing & 0.80 & 8 & 0.53 & 96 \\
Double glazing & 0.75 & 5 & 0.58 & 38 \\
\hline
\end{tabular}

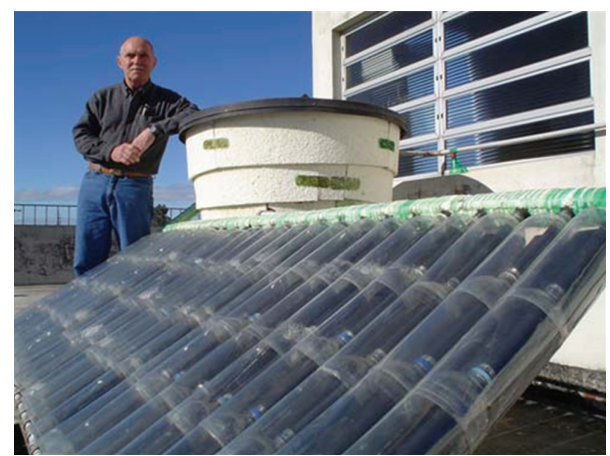

FIGURE 5: View of the tubing collector wrapped with recycled PET bottles.

by thermal sealing (which is the last design proposed for any roof) is prohibitive for a do-it-yourself project. Thus it is necessary to use simpler construction techniques to fit this requirement, as the next design shows.

2.2.3. The Tubing Collector. This collector uses many LDPE black tubing wrapped with PET glazing in order to integrate the hydraulic grid with the absorbing plate. Taking advantage of very low costs of LDPE tubes, this collector uses many thin $\left(0.5^{\prime \prime}\right)$ hoses in order to maximize the absorbing area (see Figure 5). Many collectors of this type have been constructed in Brazil, but the experience has shown that its construction is cumbersome due to the extensive fitting required. In addition, its thermal efficiency is low since it is a conventional natural-convection collector. Therefore, it has not been successful although it provides a low-cost solution available for a do-it-yourself project. Up to now there is a lack of a feasible collector that achieves all the desired goals.

\section{The New Design for Ultra-Low-Cost Collectors}

Here a new design is presented of solar collectors specially developed for exploiting the new features of plastic tubing technologies. This collector has all the advantages of previous designs and more due to a new paradigm regarding its thermal-hydraulic behavior. It is a single long LDPE hose of a large diameter connected in series between district grid and consumption. The full collector is completed with a transparent plastic layer mounted around this tube (selected among several ultra-low-cost options, like PET thin films, PET recycled soda bottles, or air-packed LDPE films) and

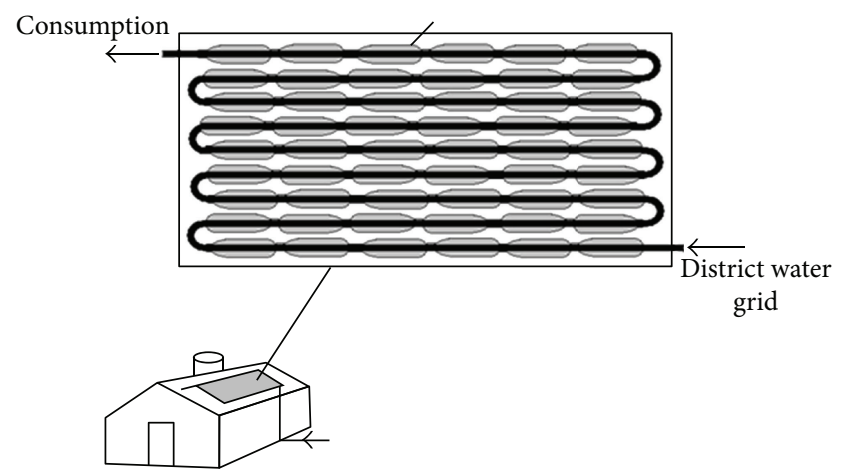

FIGURE 6: Schematic drawing of the hose collector mounted on the roof.

simply resting on the roof (see Figure 6). This way many advantages are simultaneously obtained.

First, a third option is proposed for the dilemma between natural and forced convection by using district grid as driven force, which is noticeably higher than the buoyancy force involved (about 500 times), and so a highly restricted hydraulic configuration is feasible. The consumption flow is circulated through the whole collector, but the pressure drop can be managed by choosing a large diameter hose.

Second, the storage tank is eliminated. Selecting a large diameter hose the whole water inventory is stored inside. Besides, many valves and connections are eliminated.

Third, according to its water-pond design the efficiency is very good and can collect the solar irradiance throughout the day.

Fourth, the selection of an LDPE hose allows it to manage its volumetric variations due to thermal dilatations and ice formation. LDPE provides flexible long hoses of very low costs (U\$D 60 for a $1.5^{\prime \prime}$ diameter 100 meter hose) that can withstand pressures of 6 bars or more and that still can be easily bent by heating it.

Fifth, the absorbing plate is removed. The solar irradiation is absorbed directly by the hose. This way, concerns about low thermal conductivity and high thermal gradients into the absorbing plate are avoided.

Sixth, the transparent glazing and back insulation are both provided by a single (or double for colder locations) transparent layer at a very low cost. In addition, the supporting structure is eliminated, enhancing the mechanical resistance of the collector. The black hose and the PET glazing both have excellent durability.

Seventh, the number of hydraulic joints is reduced to just one pair; this reduction is a key to guarantee the system reliability considering that barb fittings are used. 
TABLE 3: Equivalent water inventory (106 liter) obtained by different hose diameters. Flows calculated for 0.6 bar district pressure and prices for 2.5-bar hoses.

\begin{tabular}{lcccc}
\hline Diameter (inches) & Length $(\mathrm{m})$ & Max. flow (liters/min) & Normal surface $\left(\mathrm{m}^{2}\right)$ & Price $(\mathrm{U} \$ \mathrm{D})$ \\
\hline $2^{\prime \prime}$ & 56 & 212 & 3.4 & 6.6 \\
$1.5^{\prime \prime}$ & 100 & 84 & 5.6 & 50 \\
$1.25^{\prime \prime}$ & 144 & 45 & 6.8 & 80 \\
$1^{\prime \prime}$ & 224 & 20 & 9.8 & 100 \\
$0.75^{\prime \prime}$ & 400 & 6.6 & & 130 \\
\hline
\end{tabular}

TABLE 4: Parallel configurations based on many 100-meter sections for 0.6 bar district pressure. Prices include hydraulic joints.

\begin{tabular}{lccccc}
\hline Diameter (inches) & Number of lines (\#) & Max. flow (liters/min) & Inventory (liters) & Solar area $\left(\mathrm{m}^{2}\right)$ & Price $(\mathrm{U} \$ \mathrm{D})$ \\
\hline $0.5^{\prime \prime}$ & 9 & 43 & 106 & 46.0 & 200 \\
$0.75^{\prime \prime}$ & 4 & 56 & 106 & 30.7 & 150 \\
$1^{\prime \prime}$ & 2 & 60 & 95 & 19.9 & 100 \\
\hline
\end{tabular}

This design is developed intending to get the simplest collector rather than the most efficient one. This way both lowcost and home-made construction objectives are achieved. Besides, its efficiency is expected to be better than average regarding the solar pond and cylindrical shape features. These features allow it to be mounted at a nonoptimal angle, a condition desirable in order to eliminate the costs of technical installation and mechanical supporting structures.

\section{Thermal-Hydraulic Analysis}

4.1. Hydraulic Modeling. Optimizing the hydraulic behavior is key in providing the desired hot-water flow for consumption; meanwhile the large surface of the hose is excellent to collect solar energy. The maximum flow is obtained when the driving force (district-grid pressure) is balanced by all pressure drops along the line. The total pressure drop can be calculated as the sum of concentrated and distributed losses relating to the mean flow velocity $(V)$, the length $(L)$ and diameter $(D)$ of hose, and the concentrated $\left(K_{c}\right)$ and frictional $(f)$ coefficients of losses, as [12]

$$
\Delta p=\frac{1}{2}\left(K_{c}+f \frac{L}{D}\right) \rho V^{2}
$$

The frictional Darcy's coefficient $f$ is related to the flow Reynolds number $(\operatorname{Re}=V D \rho / \nu)$, based on dynamic viscosity $(\nu)$ and density $(\rho)$ of fluid; for turbulent flows into smooth pipes it can be approximated by [12]

$$
f=0.31 \operatorname{Re}^{-0.25} \text {. }
$$

On the other hand the $K_{c}$ value is related to the geometry of restriction considered; for example, considering a $100 \mathrm{~m}$ hose mounted on a roof of a 10 meter slope which is bent with a long radius curve $\left(K_{c}=2\right)$ along the edge of the roof, a total $K_{c}=20$ is obtained; since this value is much lower than the total distributed coefficient $(f L / D)$, the results are almost independent of the hose layout.

Table 3 shows the flow calculated for different hose diameters. It is observed that a $100 \mathrm{~m} 1.5^{\prime \prime}$ hose is maybe the simplest choice balancing hydraulic, solar normal area $(D *$
$L$ ), and cost behaviors and provides enough (106 liters) hot water. The thinnest hose of equivalent volume is heated very quickly but provides low flow; meanwhile a larger diameter hose $\left(2^{\prime \prime}\right)$ has a small solar area. In addition, a larger diameter implies a thicker wall $\left(5 \mathrm{~mm}\right.$ for a $2^{\prime \prime}$ hose against $3 \mathrm{~mm}$ for a $1.5^{\prime \prime}$ one considering 4-bar hoses) in order to withstand the inner pressure which in turn implies a more expensive hose and that is harder to bend. As a general rule, diameters between $1^{\prime \prime}$ and $1.5^{\prime \prime}$ are right for a simple system, providing enough flow on a modest 0.6 bar district pressure. Of course there is no single solution depending on many factors, for example, district pressure, solar resource, and climate pattern as well as practical conditions, like hose diameters available in local hardware stores and the pattern of use. For example, for application at a day school it is impractical to keep water warm during the night using a large-diameter hose (a practical technique that will be studied in the next section), and on the other hand it can be desirable to use thin hoses for quick heating in the morning.

Let us remark on the flexibility and open configuration of this design. For example, if a too thin $0.75^{\prime \prime}$ hose is selected and the flow is too low, the user could always improve it by dividing the $400 \mathrm{~m}$ long hose in two parallel $200 \mathrm{~m}$ lines; this way and according to the previous case shown in Table 3 the flow is almost tripled obtaining a very good $(19.4 \mathrm{~L} / \mathrm{min})$ flow. Table 4 illustrates different configurations based on rolls of a $100 \mathrm{~m}$ hose connected in parallel intending to achieve high flow and high solar area. This configuration allows the use of the thinnest hose possible to maximize the surface or, conversely, to use larger diameter hoses in order to lower costs.

We also could think about a "mixed assembly" intending to balance the maximum solar area and maximum flow criteria. This can be achieved by just adding an on/off valve on each parallel line, to obtain water heated quickly during the morning using a thin hose together with another fraction kept warm during the evening in the large-diameter hose. The users could use water from the most convenient line in any case supported by temperature signals. Furthermore even smarter designs could be achieved for largest systems by adding a microcontroller. This apparently sophisticated 
feature is possible using a standard garden irrigation system that costs fifty dollars.

All these features illustrate the open configuration and simplicity of this design, a key in solving user's barriers previously analyzed; after all there is nothing more accessible than an LDPE hose. Moreover, the normal surface noticeably larger than on a standard flat solar collector is useful for achieving good heating efficiencies, a characteristic reinforced by the solar-pond concept, as will be studied now.

4.2. Thermal Modeling. Together with hydraulics, the thermal analysis is a key in developing an efficient home-made collector. The thermal behavior along the daily transient is described by its dynamic modeling, in which the evolution of the normal solar flux $\left(I_{n}\right)$ must be considered. For a cylinder whose generatrix has a north-south orientation, its normal surface $S_{n}$ exposed to sun rays is independent of the azimuthal $(\psi)$ solar angle and is only related to the altitude solar angle $(\alpha)$ and the roof title angle $(\beta)$ according to

$$
\begin{gathered}
S_{n}=D L \sin (\alpha+\beta), \quad \text { if } \alpha>0 \text { (during day), } \\
\text { or } S_{n}=0 \quad \text { if } \alpha<0 \text { (during night), }
\end{gathered}
$$

Where, for any hour $(t)$ of a given day $(d)$, the solar altitude at a certain latitude $(\theta)$ location having a $\delta$ declination angle can be calculated going through (5)

$$
\begin{gathered}
\delta=23.45 \sin \left(\frac{360(d-81)}{365}\right) \quad \text { for } d=1,2, \ldots, 365, \\
\psi=\frac{360^{\circ} t}{24 \mathrm{~h}}-180^{\circ} \quad \text { for } 0<t<24 \mathrm{~h}, \\
C_{1}=\sin (\theta) \sin (\delta), \\
C_{2}=\cos (\theta) \cos (\delta), \\
S_{1}=C_{1}+C_{2} \cos (\psi), \\
S_{2}=\sqrt{1-C_{1}^{2}}, \\
\alpha=\arctan \left(\frac{S_{1}}{S_{2}}\right) .
\end{gathered}
$$

From here we can calculate the "ideal" (on a sunny day) solar power $P_{\text {irrad }}$ received in any instant, as

$$
P_{\text {irrad }}=S_{n} I_{n} \quad \text { if } \alpha>0 .
$$

The energy absorbed by the collector and the heat losses are both considered within the efficiency equation (1). So, the net power gained in any instant is

$$
P_{\text {net }}=P_{\text {irrad }} \mu=S_{n} I_{n}\left(a_{0}-a_{1} \frac{\left(T-T_{a}\right)}{I_{n}}\right) .
$$

Hence, the dynamic energy-balance equation for a hosebased collector can be numerically calculated by approximating the temperature rate by its differential increment $\left(T_{n}-\right.$ $\left.T_{n-1}\right)$ on the $n$-sime time step $(\Delta t)$ as

$$
m c_{p} \frac{d T}{d t} \approx m c_{p} \frac{T_{n}-T_{n-1}}{\Delta t}=P_{\text {net }},
$$

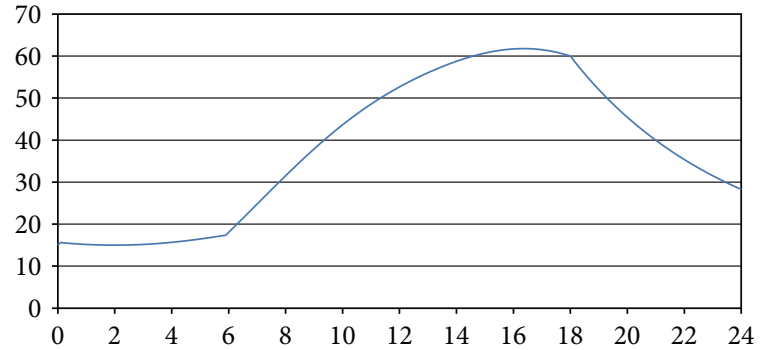

FIgURE 7: Daily temperature evolution for middle season $(d=81)$ at a temperate location.

where $m$ and $c_{p}$ are mass and heat capacity of water, respectively. From here, the temperature of collector in the $n$-sime time step can be derived as

$$
T_{n}=\frac{S_{n} a_{0} I+D L a_{1} T_{a}+\left(m c_{p} T_{n-1} / \Delta t\right)}{\left(m c_{p} / \Delta t\right)+D L a_{1}} .
$$

So, the water temperature can be numerically simulated by using this last equation during the day or modified for night use (by setting $S_{n}=0$ ) and by setting $T=T_{a}$ during the earliest hours before sunrise. For this preliminary study, the irradiance flux from the sun reaching the Earth's surface $(I)$ can be considered as constant along the day despite changes induced by atmospheric conditions, and, for simple field tests without local measurements of $I_{n}$, this constant $I$ value could be estimated from average data of the daily total irradiance $G^{\prime \prime}$ on a level surface, available from local solar maps.

Let us calculate the performance of a $1.5^{\prime \prime}$-diameter $100 \mathrm{~m}$ hose $(m=106 \mathrm{Kg}, D=0.0368 \mathrm{~m}$, and $L=100 \mathrm{~m})$ with one PET glazing $\left(a_{0}=0.8, a_{1}=8 \mathrm{~W} / \mathrm{m}^{2}{ }^{\circ} \mathrm{C}\right)$ mounted over an inclined $\left(\beta=40^{\circ}\right)$ north-oriented roof located in Buenos Aires $\left(\theta=-38^{\circ}\right)$ on 21 March $(d=81, \delta=0)$. From the Argentinean solar map [13] the monthly averaged daily solar irradiance is $G^{\prime \prime}=4.5 \mathrm{kWh} / \mathrm{m}^{2}$ and hence $I=440 \mathrm{~W} / \mathrm{m}^{2}$; in addition from climatic data $T_{a}$ can be approximated by a sinusoidal function of a half-day period of $20^{\circ} \mathrm{C} \pm 5^{\circ} \mathrm{C}$. Using this set of parameter data, the temperature evolution can be easily simulated by using a spreadsheet. The numerical convergence shows that a time step of 360 seconds provides accuracy results; using this value the temperature evolution is illustrated in Figure 7. Here different trends are observed.

(a) The temperature increases sharply from sunrise (at 6 a.m.), and useful levels (above $35^{\circ} \mathrm{C}$ ) are achieved from 8.30 a.m. to 10 p.m., which comprises the range of utilization for average users.

(b) A noticeable peak $\left(62^{\circ} \mathrm{C}\right)$ is obtained at 4 p.m., and very high levels (above $45^{\circ} \mathrm{C}$ ) are kept between 10 a.m. and 8 p.m., which provides a long range for exigent users.

(c) The temperature decreases sharply after sunset, reaching $28^{\circ} \mathrm{C}$ at midnight.

It is interesting to study the evolution of efficiency along the day, illustrated in Figure 8. The collector starts in the 


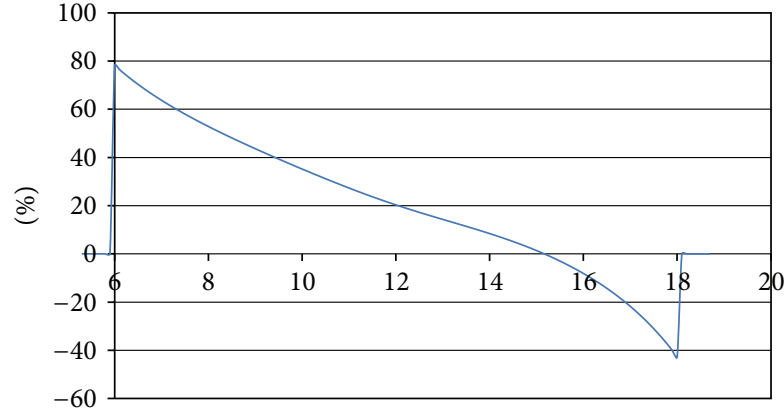

FIGURE 8: Daily evolution of efficiency for the previous case $(d=$ $81)$.

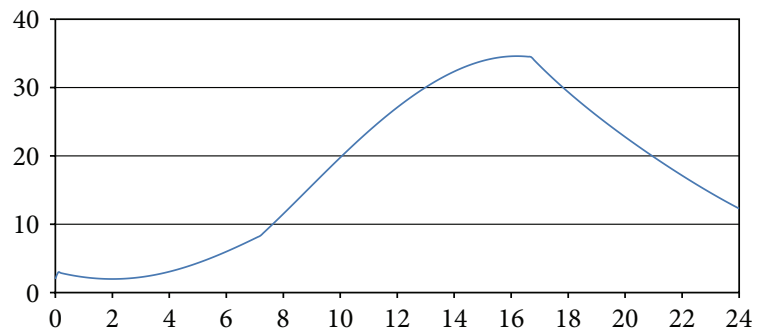

FIGURE 9: Daily temperature evolution for winter $(d=182)$ conditions.

TABLE 5: Sensitivity analysis of roof inclination for winter $(d=182)$ conditions.

\begin{tabular}{llcc}
\hline$\beta$ & $T_{\text {peak }}$ & $T$ at $6 \mathrm{pm}$ & $T$ at $8 \mathrm{pm}$ \\
\hline $0^{\circ}$ & $23^{\circ} \mathrm{C}$ & $21^{\circ} \mathrm{C}$ & $19^{\circ} \mathrm{C}$ \\
$20^{\circ}$ & $32^{\circ} \mathrm{C}$ & $29^{\circ} \mathrm{C}$ & $24^{\circ} \mathrm{C}$ \\
$40^{\circ}$ & $38^{\circ} \mathrm{C}$ & $34^{\circ} \mathrm{C}$ & $28^{\circ} \mathrm{C}$ \\
$60^{\circ}$ & $42^{\circ} \mathrm{C}$ & $37^{\circ} \mathrm{C}$ & $30^{\circ} \mathrm{C}$ \\
$80^{\circ}$ & $42^{\circ} \mathrm{C}$ & $37^{\circ} \mathrm{C}$ & $31^{\circ} \mathrm{C}$ \\
$90^{\circ}$ & $41^{\circ} \mathrm{C}$ & $37^{\circ} \mathrm{C}$ & $30^{\circ} \mathrm{C}$ \\
\hline
\end{tabular}

morning with an impressive efficiency (80\%) and reaches a useful temperature of $35^{\circ} \mathrm{C}$ at 8.30 a.m. having an average efficiency of $64 \%$ up to this moment. This fact, together with the large solar area provided by the hose (enhanced by its cylindrical shape), explains this excellent performance. On the other hand, the negative efficiency observed at night is its major drawback related to conventional collectors in which the heated water is stored into the insulated tank.

The collector shows excellent performance during the last-summer day, but the sharp decrease during the night opens a doubt about winter performance. This case is studied on 1st July $(d=182)$ for the same location $\left(G^{\prime \prime}=2 \mathrm{kWh} / \mathrm{m}^{2}\right.$, so $I=250 \mathrm{~W} / \mathrm{m}^{2}$, and $T_{a}=10^{\circ} \mathrm{C} \pm 8^{\circ} \mathrm{C}$ ) in Figure 9 . Here, it is observed that the collector becomes a useful preheater during the day but never provides hot water. This performance can be improved by adding a second glazing layer $\left(a_{0}=0.75\right.$, $a_{1}=5 \mathrm{~W} / \mathrm{m}^{2}{ }^{\circ} \mathrm{C}$ ). This way a minor improvement is obtained, with a peak temperature $\left(38^{\circ} \mathrm{C}\right)$ higher than the previous value $\left(34^{\circ} \mathrm{C}\right)$.

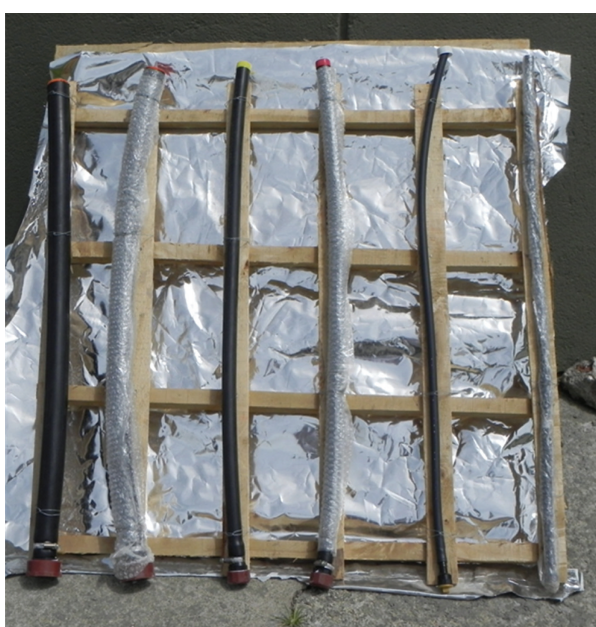

FIGURE 10: A simple test facility example.

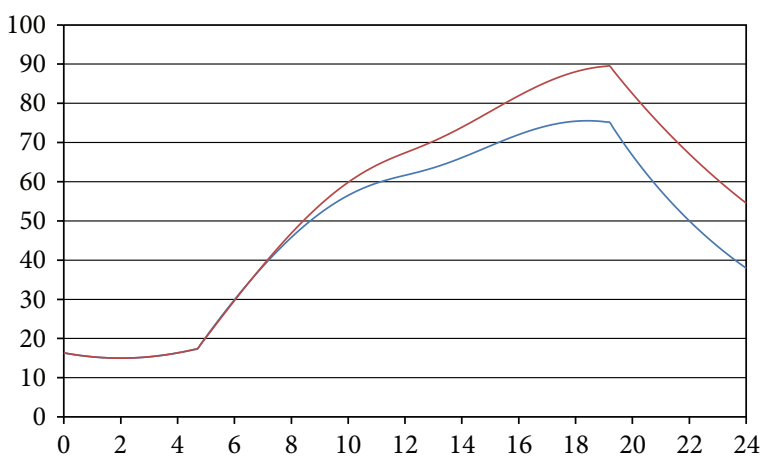

FIGURE 11: Temperatures in summer $(d=1)$ for simple and double glazing.

TABLE 6: Sensitivity analysis of hose diameter for winter conditions and $\beta=60^{\circ}$.

\begin{tabular}{lccc}
\hline Diameter & $T_{\text {peak }}$ & $T$ at $6 \mathrm{pm}$ & $\mathrm{T}$ at $8 \mathrm{pm}$ \\
\hline $0.5^{\prime \prime}$ & $53^{\circ} \mathrm{C}$ & $36^{\circ} \mathrm{C}$ & $22^{\circ} \mathrm{C}$ \\
$0.75^{\prime \prime}$ & $50^{\circ} \mathrm{C}$ & $39^{\circ} \mathrm{C}$ & $27^{\circ} \mathrm{C}$ \\
$1^{\prime \prime}$ & $47^{\circ} \mathrm{C}$ & $39^{\circ} \mathrm{C}$ & $29^{\circ} \mathrm{C}$ \\
$1.25^{\prime \prime}$ & $44^{\circ} \mathrm{C}$ & $38^{\circ} \mathrm{C}$ & $30^{\circ} \mathrm{C}$ \\
$1.5^{\prime \prime}$ & $41^{\circ} \mathrm{C}$ & $37^{\circ} \mathrm{C}$ & $30^{\circ} \mathrm{C}$ \\
$2^{\prime \prime}$ & $37^{\circ} \mathrm{C}$ & $34^{\circ} \mathrm{C}$ & $30^{\circ} \mathrm{C}$ \\
\hline
\end{tabular}

Several sensitivity analyses can be performed for this last condition. Table 5 shows that collectors mounted on roofs with a steep incline get higher temperatures that those mounted on barely inclined roofs as those use better the evening sun rays. This way, the peak temperature obtained for a level-surface roof is just $23^{\circ} \mathrm{C}$ against $42^{\circ} \mathrm{C}$ for another inclined $60^{\circ}$. The influence of hose diameter is shown in Table 6, showing that thinner hoses get higher temperatures but their cooling at night is sharper too. Again here, the best choice is found between $1^{\prime \prime}$ and $1.5^{\prime \prime}$ hoses. Figure 10 shows a simple test facility that comprises three "naked" hoses $\left(0.5^{\prime \prime}\right.$, $1^{\prime \prime}$, and $1.5^{\prime \prime}$ ) and similarly the same hoses but wrapped with 


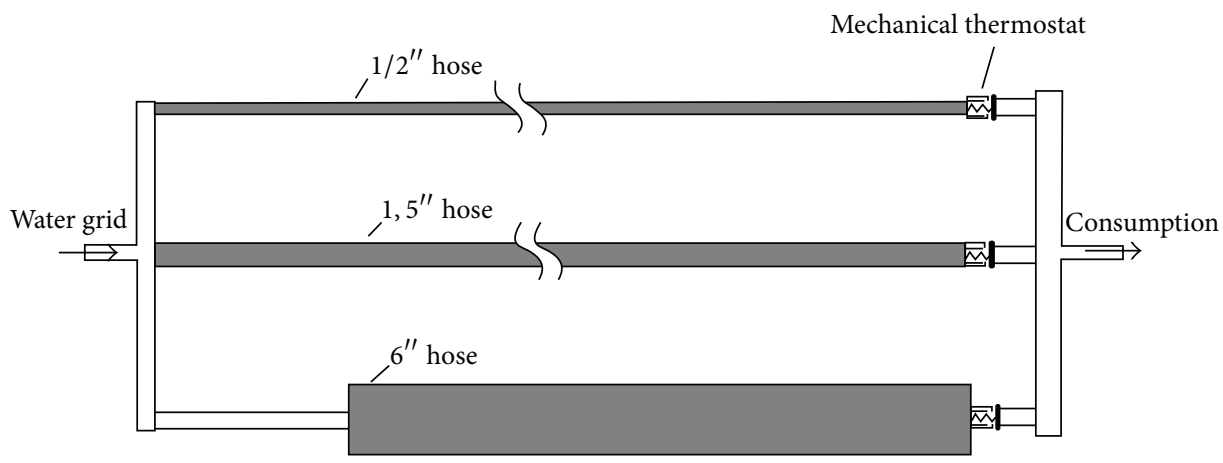

FIGURE 12: Schematic drawing of the three-line mixed system.

TABle 7: Performance of the three-line system by using previous conditions $\left(\beta=40^{\circ}\right)$.

\begin{tabular}{lccccrr}
\hline \multirow{2}{*}{ Diameter } & \multicolumn{2}{c}{ Summer $(d=1)$} & \multicolumn{2}{c}{ Autumn $(d=81)$} & \multicolumn{2}{c}{ Winter $(d=182)$} \\
& $T_{\text {peak }}$ & $T$ at $10 \mathrm{p} . \mathrm{m}$. & $T_{\text {peak }}$ & $T$ at $10 \mathrm{p} . \mathrm{m}$. & $T_{\text {peak }}$ & $T$ at $10 \mathrm{p} . \mathrm{m}$. \\
\hline $6^{\prime \prime}$ & $53^{\circ} \mathrm{C}$ & $50^{\circ} \mathrm{C}$ & $42^{\circ} \mathrm{C}$ & $39^{\circ} \mathrm{C}$ & $23^{\circ} \mathrm{C}$ & $20^{\circ} \mathrm{C}$ \\
$1.5^{\prime \prime}$ & $76^{\circ} \mathrm{C}$ & $46^{\circ} \mathrm{C}$ & $65^{\circ} \mathrm{C}$ & $33^{\circ} \mathrm{C}$ & $35^{\circ} \mathrm{C}$ & $14^{\circ} \mathrm{C}$ \\
$0.5^{\prime \prime}$ & $82^{\circ} \mathrm{C}$ & $25^{\circ} \mathrm{C}$ & $73^{\circ} \mathrm{C}$ & $16^{\circ} \mathrm{C}$ & $40^{\circ} \mathrm{C}$ & $6^{\circ} \mathrm{C}$ \\
\hline
\end{tabular}

double layer of air-packed transparent polyethylene film, a very low-cost glazing $\left(0.3 \mathrm{USD} / \mathrm{m}^{2}\right)$.

Finally, it is interesting to study the performance on hot summer days (1st January, $d=1$ ) at this temperate location $\left(T_{a}=25^{\circ} \mathrm{C} \pm 10^{\circ} \mathrm{C}, G^{\prime \prime}=6.5 \mathrm{kWh} / \mathrm{m}^{2}\right.$ so, $\left.I=500 \mathrm{~W} / \mathrm{m}^{2}\right)$ on a $60^{\circ}$ inclined roof. Figure 11 compares temperatures for single and double glazing for this case. Here we observe that both systems provide enough hot water throughout the day, but the double glazing reaches a dangerous peak of $90^{\circ} \mathrm{C}$, a temperature too high for LDPE. Of course the flow of consumption is a simple way to limit this effect, but the system must withstand extreme cases, like, for example, during the holidays. Thus, this behavior should be checked before choosing reinforced insulation.

Regarding this concern about overheating, it is interesting to study the thermal performance of a "mixed system" built with several hoses of different diameters assembled on the parallel layout illustrated in Figure 12. In this example we consider the following.

(a) A 6" PVC tube of 8-meter length (106 liters) with double glazing.

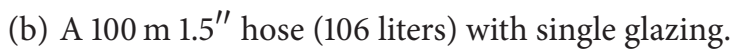

(c) A $100 \mathrm{~m} 0.5^{\prime \prime}$ hose (12 liters) with single glazing.

This way we simultaneously obtain the following.

(i) A small volume of quickly heated water in the morning (by the $0.5^{\prime \prime}$ hose) that can be quickly "replenished" every hour.

(ii) A large volume (106 liters) available throughout the day and evening.

(iii) A large volume (106 liters) kept warm overnight.
The user could choose the most convenient line at any time, or this choice could be automatized by using lowcost microcontrolled on/off valves. Another simple solution consists in adding a bimetallic thermostat on the exit of each line. This option is less flexible than the previous one, but the thermostat is a very reliable and low-cost device.

The use of a very large diameter $\left(6^{\prime \prime}\right)$ is useful to provide hot water throughout the night, and besides it supports the choice of using single glazing on the thinner hoses, this way avoiding dangerous overheating during hot summer days. Table 7 shows the results of the thermal simulation of this system, by using the same cases previously studied. Here is observed that all objectives are successfully achieved.

\section{Conclusions}

This paper presents a new design of a low-cost and robust solar collector. It was developed intending to fit the lack of a simple, home-made, and self-installation device, a key for success in developing countries. To achieve simultaneously all these goals, a new thermal-hydraulic paradigm was proposed from which we have created a new design for a solar collector that takes full advantage of new plastic and tubing technologies. Although rather similar designs are well known from the open literature, the comprehensive thermal and hydraulic discussion (for both stationary and daily transient states) developed here is a worthy contribution of this work. On this base, it is easy to "tune up" the collector regarding the specific solar and climate resources, among other issues. In this way, different hose diameters and glazing can be used in order to obtain the best solution for any case. The use of controlling systems and mixing configurations are also costeffective options to enhance the performance.

In this paper the deeply rooted thermal-hydraulic paradigm of conventional collectors is discussed. In addition, 
this work presents the advantages of the water-pond design, which has long been known, but its benefits have never been acknowledged [14]. The improved efficiency of water ponds regarding conventional solar collectors is a key to achieve efficient low-cost collectors even in temperate climates.

\section{Acknowledgments}

Argentinean Du Pont enterprise is acknowledged for its support by funds given through the National Prize Du Pont to Clean Energies 2009 to this project. Grace De Haro is acknowledged for her careful translation.

\section{References}

[1] S. Ozlu, I. Dincer, and G. F. Naterer, "Comparative assessment of residential energy options in Ontario, Canada," Energy and Buildings, vol. 55, pp. 674-684, 2012.

[2] L. T. Kostić and Z. T. Pavlović, "Optimal position of flat plate reflectors of solar thermal collector," Energy and Buildings, vol. 45, pp. 161-168, 2012.

[3] M. Khalaji Assadi, A. Khalesi Doost, A. A. Hamidi, and M. Mizani, "Design, construction and performance testing of a new system for energy saving in rural buildings," Energy and Buildings, vol. 43, no. 12, pp. 3303-3310, 2011.

[4] Sociedade Do Sol, http://www.sociedadedosol.org.br/.

[5] L. Juanicó, "A new design of roof-integrated water solar collector for domestic heating and cooling," Solar Energy, vol. 82, no. 6, pp. 481-492, 2008.

[6] L. E. Juanicó, "A new design of configurable solar awning for managing cooling and heating loads," Energy and Buildings, vol. 41, no. 12, pp. 1381-1385, 2009.

[7] L. E. Juanicó, "New design of solar roof for household heating and cooling," International Journal of Hydrogen Energy, vol. 35, no. 11, pp. 5823-5826, 2010.

[8] R. Sarachitti, C. Chotetanorm, C. Lertsatitthanakorn, and M. Rungsiyopas, "Thermal performance analysis and economic evaluation of roof-integrated solar concrete collector," Energy and Buildings, vol. 43, no. 6, pp. 1403-1408, 2011.

[9] H. R. Hay and J. I. Yellott, "International aspects of air conditioning with movable insulation," Solar Energy, vol. 12, no. 4, pp. 427-430, 1969.

[10] E. Aranovitch, "Heat transfer processes in solar collectors," Energy and Buildings, vol. 3, no. 1, pp. 31-47, 1981.

[11] P. T. Tsilingiris, "Towards making solar water heating technology feasible-the polymer solar collector approach," Energy Conversion and Management, vol. 40, no. 12, pp. 1237-1250, 1999.

[12] F. White, Fluid Mechanics, McGraw-Hill, New York, NY, USA, 6th edition, 2006.

[13] R. Righini, H. G. Gallegos, and C. Raichijk, "Approach to drawing new global solar irradiation contour maps for Argentina," Renewable Energy, vol. 30, no. 8, pp. 1241-1255, 2005.

[14] M. N. A. Hawlader and B. J. Brinkworth, "An analysis of the non-convecting solar pond," Solar Energy, vol. 27, no. 3, pp. 195$204,1981$. 


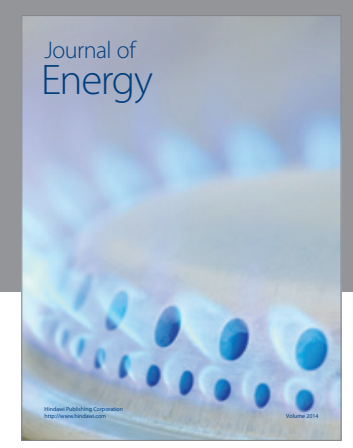

Journal of

Industrial Engineering
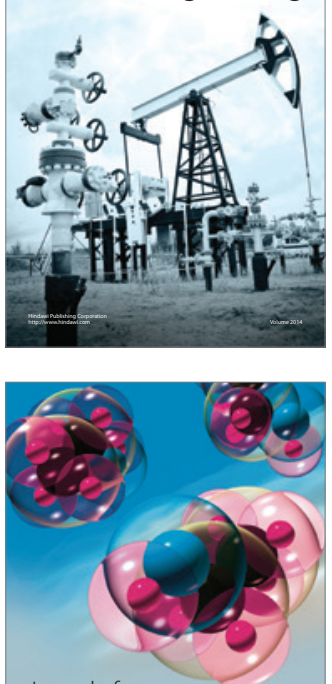

Fuels
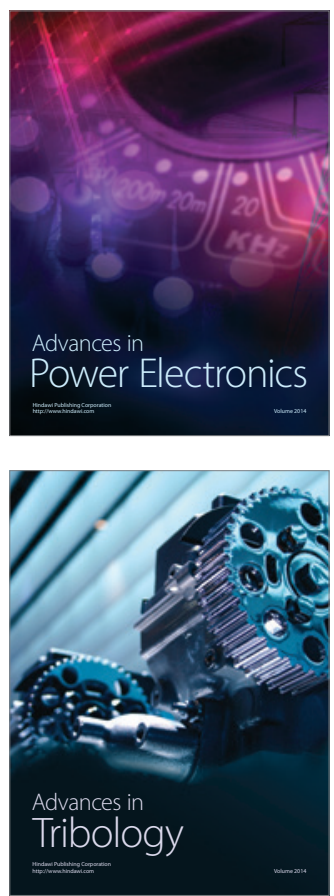

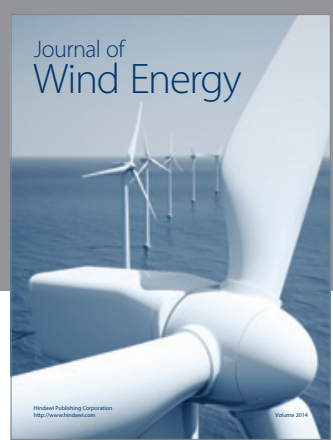

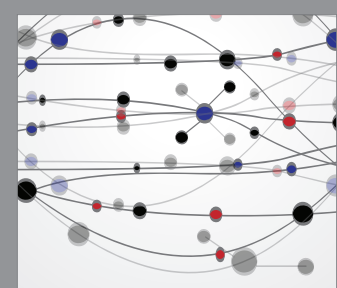

The Scientific World Journal

Submit your manuscripts at http://www.hindawi.com

Journal of

Structures
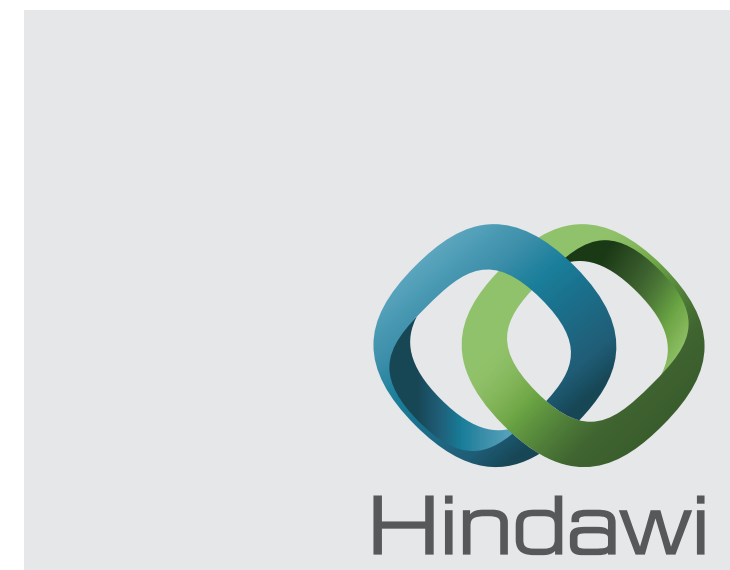

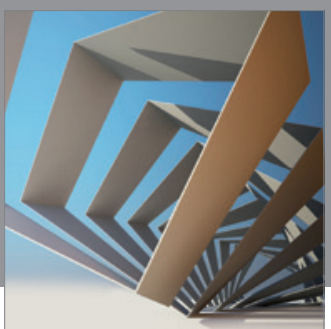

Rotating

Machinery
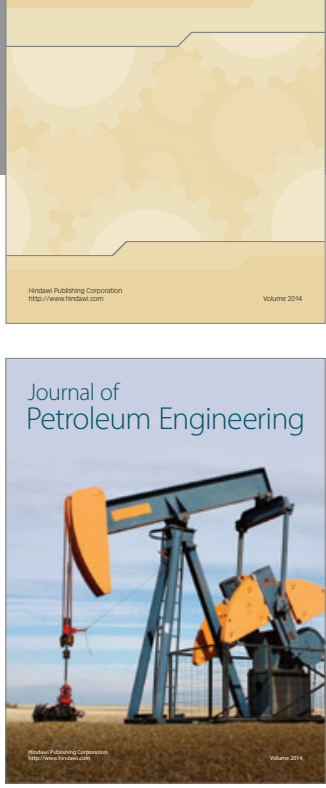

Journal of

Solar Energy
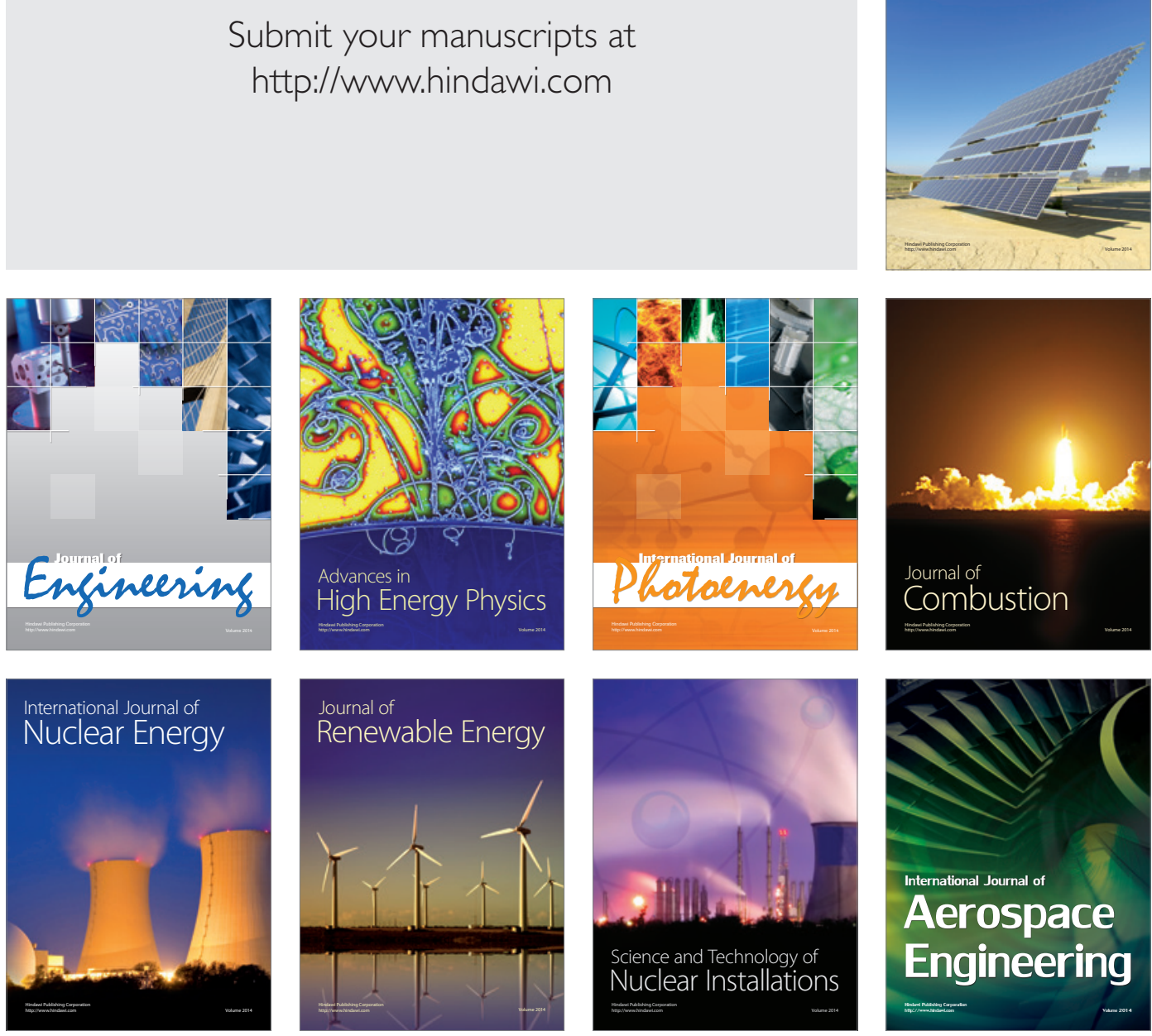